\title{
Managing stress for health!
}

\author{
Volume 3 Issue 6 - 2016 \\ Jane Smolnik \\ Iridologist, Ultimate Healing, North Carolina
}

\section{Opinion}

Stress is a part of living - things happen! But UN-managed stress can really take a toll on our health and vitality. You can feel tired, agitated, irritable, depressed, have headaches, brain fog, anxiety, insomnia, poor digestion, low sex drive, and more. Learning to recognize WHERE our stress comes from and managing it well is essential for our health and well-being (Figure 1).

We live in a fast-paced world and most of us have adapted to a level of chronic stress, leaving our sympathetic nervous system constantly in the 'ON' state producing a stream of stress hormones which we really don't need. Stress creates a lot of free-radicals in the body which contribute to cellular aging, exhaustion, poor immunity and weight gain. When you are in a stress-response, your sympathetic nervous system will turn glycogen into glucose (sugar) to increase your energy. It also reduces your digestion and elimination, so we see chronic problems there as well.

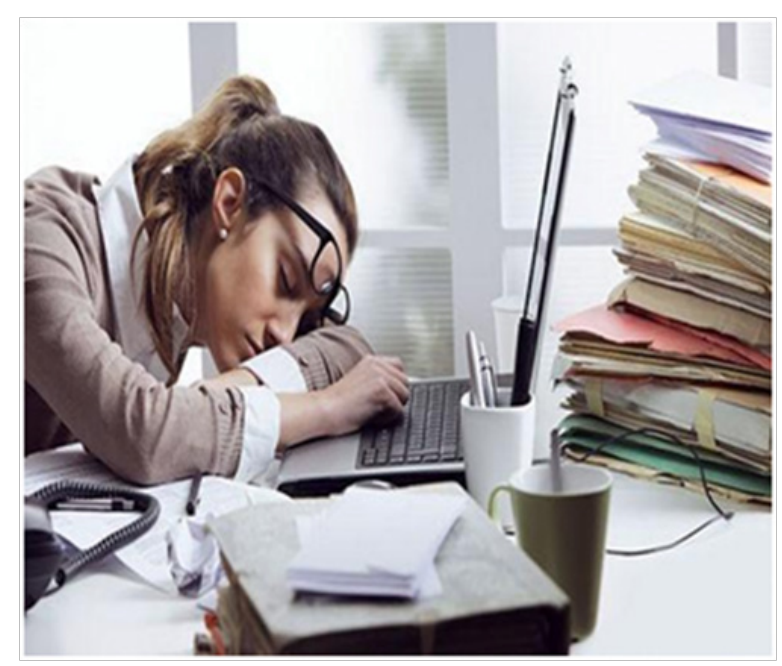

Figure I Managing stress for health.

In 2014 it is estimated that we now spend 9.8hours a day of media exposure on computers, tablets, TV's, and cell phones! Think of the constant mental stimulation from processing images and information constantly! Most of us have media-stress and tired brains. I know I feel it when I spend too much time on my computer or scrolling on Face book!

The problem is that so much brain stimulation increases output of stress hormones like adrenaline, cortisol and epinephrine. This can leave your adrenals exhausted after a while and not able to produce the proper stress hormones when you need it. I have suffered from adrenal exhaustion, twice, (a bit of an over-achiever!) and had to rebuild and recover. It's not easy once you reach the stage of adrenal exhaustion. You cannot live without your adrenals! It can take anywhere from two months to two years to recover.

\begin{abstract}
Correspondence: Jane Smolnik, Iridologist, Ultimate Healing, I2-A Cedarwood Ct.,Asheville, North Carolina, Tel 828-7775263,Email drjanesmolnik@gmail.com
\end{abstract}

Received: May 20, 2016 | Published: May 31, 2016
We can also have many other stressors, like relationship stress, financial problems, work issues, health issues, death or illness of loved ones, environmental toxins, poor food quality, nutritional deficiencies, hidden parasites, viral infections, yeast, and more. Many people don't realize that your body can be in a chronic stress state even if you don't feel emotionally stressed at the moment.

Perhaps it's best to learn how you can get your stress response under control!

\section{Here are some tips for reducing stress:}

1. Examine how much time you spend on social media, computers, tablets, news, etc. Be honest with yourself and reduce this time daily.

2. Replace some of this time with quiet time, listening to relaxing music, taking walks outside, or other physical activities.

3. Try a new hobby, yoga, meditation, dancing, swimming, hiking, coloring or painting!

4. Avoid stimulants like caffeine, sugar and energy drinks that will deplete you quicker.

5. Eat simple whole foods and eat slower, chewing thoroughly, Do not skip meals. Have fruit and/or veggies for snacks for a potassium and sodium boost.

6. SLOW DOWN! Avoid chronic rushing, driving fast. Learn to pace yourself.

7. Avoid worrying. Relax and take some DEEP cleansing breaths whenever you feel stressed!

8. Get connected with people you care about, and who care about you! Talk and share more with loved ones and friends.

9. Keep your home neat, and make your bedroom a sanctuary. No electronics in the bedroom! Avoid electronic screens at least 2 hours before bed. Read a real book, chat, or meditate. 
10. Spend some time outdoors EVERYDAY! Just taking a 10minute walk can greatly reduce stress and rebalance your nervous system.

Stress can be reduced when you incorporate a practice of self-care skills! It is essential in this day and age, and also good to teach our young kids to do as well. Your body will feel more balanced, your mind will be clearer, you will digest better, you will have better hormone production and you will control your weight easier, sleep better, feel happier, and be a joy to be around! Start today creating healthier habits.

\section{Acknowledgments}

None.

\section{Conflicts of interest}

Author declares there are no conflicts of interest.

\section{Funding}

None. 